\title{
sciendo
}

ISSN: $1231-4005$

e-ISSN: $2354-0133$

DOI: $10.2478 /$ kones-2019-0093

\section{VALIDATION OF MICROSCOPY MEASURED POROSITY IN CARBON FIBBERS COMPOSITES}

\author{
Arnold Jędral, Anna Bona \\ Eukasiewicz Research Network - Institute of Aviation \\ Centre of Composite Technologies \\ Composite Testing Laboratory \\ KrakowskaAv.110/114,02-256 Warsaw, Poland \\ e-mail: arnold.jedral@ilot.edu.pl,anna.bona@ilot.edu.pl
}

\begin{abstract}
One of the most common defects in carbon fibre reinforced plastics (CFRP) is porosity. Too much of those defects could be serious problems to mechanical properties, which directly take effect on elements safety, like aircrafts. Therefore, the evaluation of porosity is very important test. Microscopic observations are widely used as a quality instrument in materials and constructions inspections. Cross section image of a material is easy to prepare and analyse. Porosity of a carbon fibre reinforced plastic can be clearly spot in such kind of images. Study shows that in the most cases porosity appear between layers of fibres, rather between fibres. Unfortunately, image from microscope is only $2 D$ picture from a small representative region. Because of that, comparison of $2 D$ image to a real porosity distribution in all volume of a material is very difficult. To verify $2 D$ microscopic observation method is necessary to perform another kind of tests. In this article, authors focused on non-destructive (NDT) and destructive testing methods. $2 D$ porosity images from light microscope were compared with three different testing methods: ultrasonic test (UT), computed tomography (CT) test and constituent content of composite materials standard test method according to ASTM D3171 - 15, procedure B. Porosity results obtained from dissolution of resin from the carbonepoxy resin sample.
\end{abstract}

Keywords: porosity, carbon fibre, microscope, UT (Ultrasonic test), CT (computed tomography)

\section{Introduction}

Porosity is one of many factors, which decrease mechanical properties of carbon fibre composite materials [1-3].

Since composites appear in aircrafts, producers tried to minimize presence of porosity in structures. To reach that goal they used many different processes, parameters for each process, materials and different quality check procedures.

One of that quality tool is microscopy observation. This could be done on previously prepared sample, which will show a cross section of bigger element. Cross section of a sample represents structure of a whole element. On carbon fibre - epoxy resin composite cross section, is possible to see fibres or even single fibre, surrounding resin and defect that appear during production process. From defects, porosity can be mainly seen but others are fibre waviness/misalignment, delamination and broken fibres.

It appears mostly between layers of fibres, it can be spot as a lack of resin in resin rich regions (RRR) and rather between fibres. Microscopy observations can be quickly done and they give real image of the structure, which makes them very interesting quality tool in any industry (Fig. 1). However, there are an issues, it is destructive method, can introduce artifacts into structure and image from the microscope is only in 2D. It does not show structure in whole sample volume. Based on this, it is difficult to predict how porosity and structure of composite in general, looks like.

Another widely used inspection test is based on an ASTM D3171, procedure B [5]. This method is dedicated to measurement constituent content in composites but knowing densities of 
each components like a fibre and resin is possible to count porosity [6-10]. Constituent content of composite materials tests have few steps. Every testing specimen should be weighted to the nearest $0.0001 \mathrm{~g}$. Determine the density, used Archimedes method, in accordance with ASTM D792 test method [6]. To degrade components sulfuric acid $\mathrm{H}_{2} \mathrm{SO}_{4} 96 \%$ should be used. When the solution is dark (Fig. 2), the hydrogen peroxide $\mathrm{H}_{2} \mathrm{O}_{2}, 30 \%$ should be added. Used pre weighted crucibles to filter, the contents using distilled water. Last step is drying the specimen at $100^{\circ} \mathrm{C}$ minimum (Fig. 3).
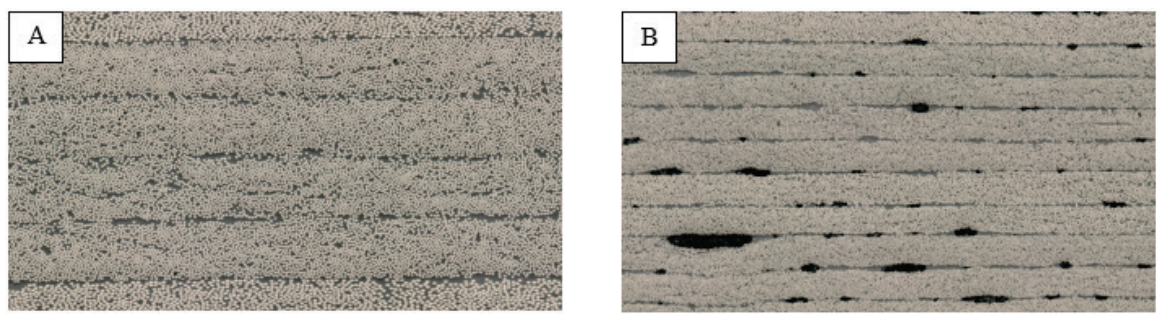

Fig. 1. Cross-section images of composite: without porosity (A), visible regions of porosity and resin rich regions (B) [A.J.2018]

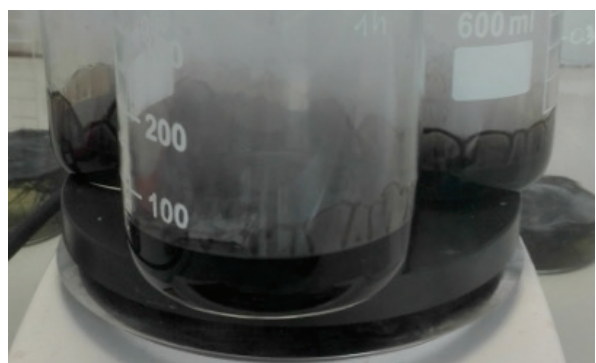

Fig. 2. Components degradation after using $\mathrm{H}_{2} \mathrm{SO}_{4} 96 \%$ [10]

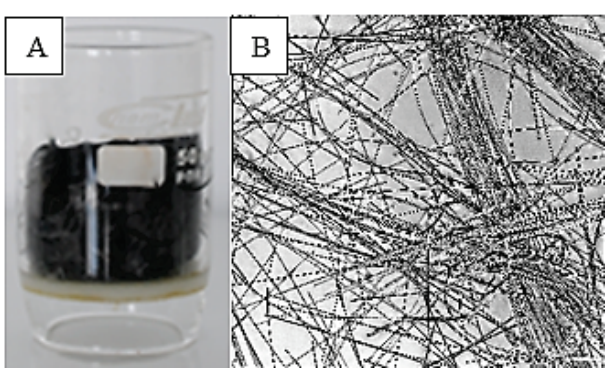

Fig. 3. Carbon fibres after extraction process: $A$ - fibres in filter [10], B - fibres seen on microscope (mag. x300) [A.J.2018]

Calculations of the test method are shown below:

a) reinforcement content - weight percent:

$$
W_{r}=\left(M_{f} / M_{i}\right) \times 100,
$$

where: $M_{i}$ - specimen initial mass, $\mathrm{g}, M_{f}$ - specimen final mass, $\mathrm{g}$,

b) reinforcement content - volume percent:

$$
V_{r}=\left(M_{f} / M_{i}\right) \times 100 \times \rho_{c} / \rho_{r},
$$

where: $\rho_{c}$ - reinforcement density, $\mathrm{g} / \mathrm{cm}^{3}, \rho_{r}-$ specimen density, $\mathrm{g} / \mathrm{cm}^{3}$,

c) matrix content - weight percent:

$$
W_{m}=\left(M_{i}-M_{f}\right) / M_{i} \times 100,
$$

d) matrix content - volume percent:

$$
V_{m}=\left(M_{i}-M_{f}\right) / M_{i} \times \rho_{c} / \rho_{m} \times 100,
$$

where: $\rho_{m}-$ matrix density, $\mathrm{g} / \mathrm{cm}^{3}$,

e) void volume:

$$
V_{v}=100-\left(V_{r}+V_{m}\right) .
$$

To see more need to use method where material will be scanned trough it whole volume, will not interact with it and do not destroy it. This can be possible with x-ray radiation. Computed tomography (CT) is becoming increasingly important in composite quality inspections [11-13]. CT 
provides high-resolution 3D images of composite architectures, defects occurred during manufacturing and in-service. This method is a non-destructive technique so it allows inspecting materials also during manufacturing or being loaded during test and track evolution of defects. Principle of operation of CT is that object under investigation is placed between x-ray source and detector on a rotating table. Number of a projections are collected over 360 degrees (Fig. 4).

When an x-ray beam passes through an object, a radiograph can be done, which is a projection of the absorption coefficients of the structures of the sample. Back-projection algorithm can then be used to reconstruct the distribution of absorption coefficients through the volume of the sample. The result gained after projection is local attenuation coefficient of the x-rays measured in a unit called a voxel (it is like a pixel with three dimensions). The resulting data can be analysed to obtain 3D information about the microstructure (Fig. 5). In this article, authors compared previously mentioned methods for porosity measurement in carbon/epoxy composite materials.

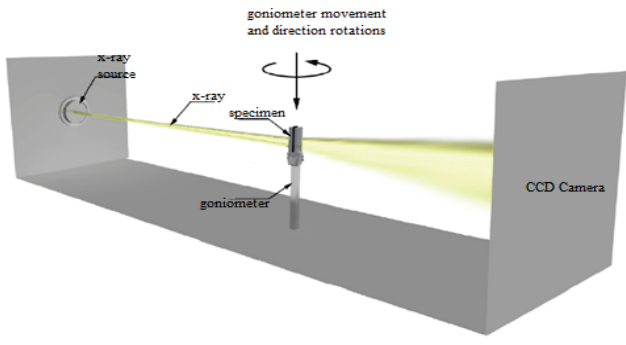

Fig. 4. Schematic view of specimen scanning in tomograph chamber [12]

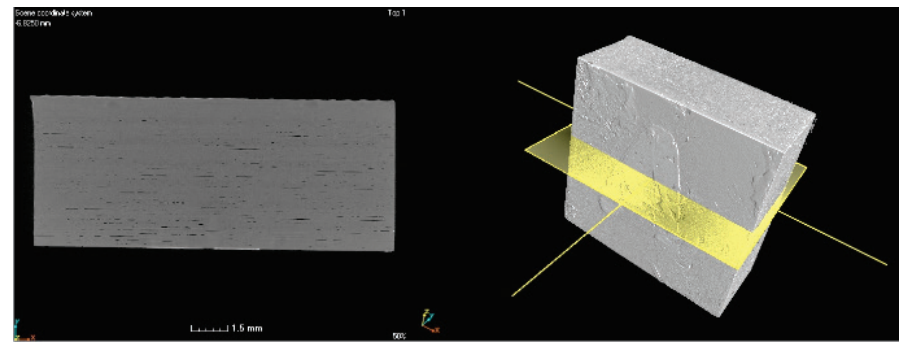

Fig. 5. 3D and selected cross-section image of carbon fibre composite specimen [A.J. 2018 ]

\section{Samples preparation}

Samples were cut from larger panels prepared in automated fibre placement technology (AFP). Panel was made from 44 layers of carbon fibre covered by thermosetting resin.

\section{UT (Ultrasonic test)}

After manufacturing process, panels were checked in non-destructive test (NDT) based on propagation of ultrasonic wave (UT - ultrasonic test) [14], to spot if there are places with defects. Example of that UT test represents Fig. 6. Based on UT results, different regions with different expected porosity have been chosen to prepare samples. Regions chosen for evaluation were marked in Fig. 7.

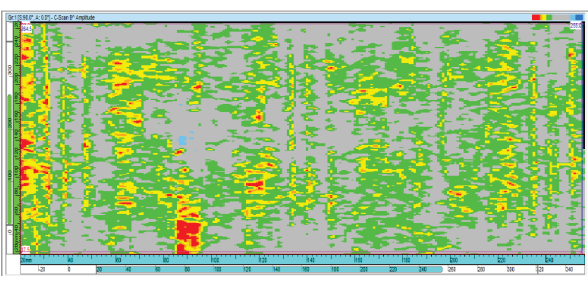

Fig. 6. UT result (red/yellow regions represent low quality of the panel, green - medium, grey/blue - good) [R.S. 2018]
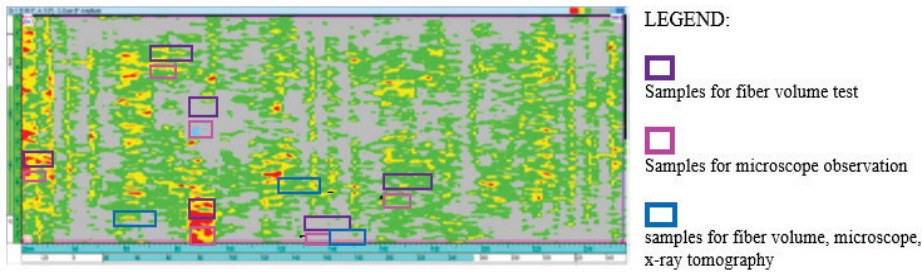

Fig. 7. UT result with places marked for evaluation

According to UT, each colour on the picture refers to different strength of reverse signal recorded by the detector. Different colours means that signal met other structure on its way back through the sample. That could be all kinds of defects that were mention before, so delamination, debonding, RRR, foreign objects or porosity. Assuming (and later confirmed) that in this case any delamination, debonding, fibre mismatch, etc. did not occur; it could be porosity or RRR. Based on that, ranges of percentage porosity/resin rich regions content were determined. Values of determined ranges are presented in Tab. 1. 
Tab. 1. Values of porosity/resin rich regions according to UT strength signal

\begin{tabular}{|l|l|c|}
\hline \multicolumn{2}{|c|}{ Colour } & Predicted porosity percent \\
\hline navy blue & \multicolumn{2}{|c|}{$0-0.4$} \\
\hline blue & & $0.02-0.5$ \\
\hline grey & & $0.18-1.9$ \\
\hline green/yellow & & $1.35-3.25$ \\
\hline red & & $>4.86$ \\
\hline
\end{tabular}

\section{Microscope observation}

Microscope observations (MIC) were done on optical microscope with magnification in range from 100 to 300 times. Before that, samples were grinded and polished to get the best surface preparation. Based on greyscale on each picture of each sample, porosity measurement was done (Fig. 8).

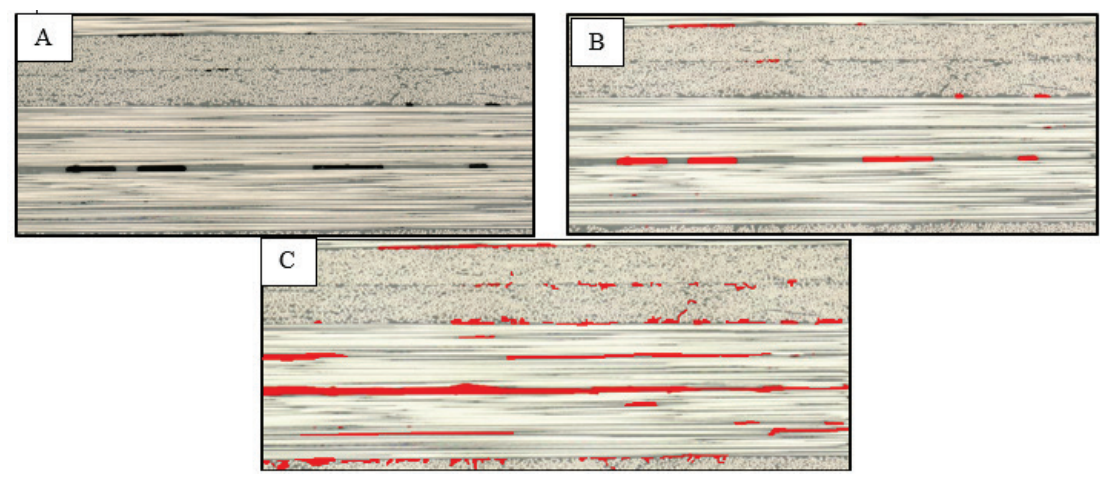

Fig. 8. 2D images from microscope: A-raw image of the sample, $B$-porosity marked based on greyscale $C$ - porosity and resin rich regions marked based on grey scale) [A.J. 2018]

Results from microscopy observations presented in Tab. 2 shows that there is a connection with results from UT. Regions, which were marked as those with higher porosity (red or yellow colour) shows worst structural condition of the material than those, marked on grey or blue colour. On microscopic pictures is visible that this bad regions have porosity but also they have much more regions rich with resin. Ultrasonic wave penetrating material through it thickness, encounter porosity and RRR. This objects change the way that ultrasonic wave reflect from them. This is answer why on UT scans marked regions shows higher porosity than they have in practice. Real porosity measurement result is lower than this got from UT because it did not contain RRR into calculation.

Another observation is that porosity in most cases is located inside RRR. This means it is a residue area left after matrix curing. These regions appear mostly between layers of carbon fibres. Much less often porosity appears inside single layer of carbon fibres.

Tab. 2. Optical microscopy porosity measurement results containing pure porosity and resins rich regions

\begin{tabular}{|c|c|c|}
\hline Region & Porosity [\%] (without RRR) & Porosity [\%] (with RRR) \\
\hline 1 & 0.636 & 1.644 \\
\hline 2 & 0.704 & 1.500 \\
\hline 3 & 0.576 & 1.069 \\
\hline 4 & 0.731 & 1.402 \\
\hline 5 & 0.504 & 0.917 \\
\hline 6 & 0.332 & 1.281 \\
\hline A & 1.152 & 2.912 \\
\hline B & 0.885 & 2.724 \\
\hline C & 0.832 & 1.812 \\
\hline
\end{tabular}


During observations it was seen, that in some cases porosity was closed by mounting resin, in which samples are placed for grinding, polishing preparation. This situation leads to understatement of porosity measurement results. It is possible that on previous tests, some of RRR were rich in resin comes from outside (not from the composite manufacturing process). When samples are not in mounting resin, results from CT and UT are closer to this got from microscope measurement. Mounting resin is used for making grinding, polishing process faster and more accurate but liquid, in first few hours, resin can penetrate dipped sample and cure inside.

Effect of porosity closure by mounting resin, was examined by making cross sections of samples prepared in epoxy mounting resin and without it. Before, samples were checked on CT and UT to have better comparison. Measurement result from microscope is an average from 4 cross sections made every $1.5 \mathrm{~mm}$ of sample thickness (Tab. 3). Values on UT row, describe signal strength of ultrasonic wave, which return to detector after going through the material. Higher value means that, most of signal returned to detector, thus porosity is low. Values are in percent.

Tab. 3. Porosity results of samples prepared in two methods

\begin{tabular}{|c|c|c|c|}
\hline Sample & MIC & CT & UT \\
\hline $6-2-5$ & 1.212 & 2.75 & 17.2 \\
\hline $10-1-3$ & 0.996 & 2.21 & 20.2 \\
\hline $11-1-4$ & 0.550 & 0.66 & 39.76 \\
\hline $6-1-6$ & 1.383 & 2.62 & 16.79 \\
\hline $9-1-1$ & 1.331 & 1.9 & 19.44 \\
\hline $11-1-1$ & 0.922 & 1.82 & 26.04 \\
\hline $6-2-8$ & 1.315 & 1.76 & 22.84 \\
\hline \multicolumn{4}{|c|}{ Samples in mounting resin } \\
\hline
\end{tabular}

\begin{tabular}{|c|c|c|c|}
\hline Sample & MIC & CT & UT \\
\hline $10-4$ & 0.885 & 2.00 & 27.33 \\
\hline $6-2-9$ & 1.004 & 1.22 & 32.3 \\
\hline $15-4$ & 0.083 & 0.37 & 73.73 \\
\hline $6-2-1$ & 1.749 & 2.74 & 11.25 \\
\hline $6-1-1$ & 0.966 & 1.38 & 37.87 \\
\hline $15-2$ & 0.347 & 0.99 & 49.98 \\
\hline $6-1-5$ & 0.878 & 1.64 & 21.91 \\
\hline \multicolumn{4}{|c|}{ Samples without mounting resin } \\
\hline
\end{tabular}

Use of coloured, fluorescent mounting resin allowed doing observation on UV light and confirming that mounting resin could be a reason of pores closure. To compare results from measuring methods, correlation coefficient were calculated between MIC and CT, MIC and UT, UT and CT. Results have better correlation when they were not in mounting resin (Tab. 4). It is confirmation that resin can transfer inside the sample during preparation for grinding/polishing process, and it is a reason of porosity understatement.

Tab. 4. Correlation coefficient between MIC, UT, and CT

\begin{tabular}{|l|c|c|c|}
\hline \multicolumn{1}{|c|}{ Correlation coefficient } & MIC vs CT & MIC vs UT & CT vs UT \\
\hline Samples in mounting resin & 0.9143 & -0.9080 & -0.9232 \\
\hline Samples without mounting resin & 0.7497 & -0.8879 & -0.9450 \\
\hline
\end{tabular}

\section{Computed tomography (CT)}

Computed tomography was the last of non-destructive methods, which were used. Places from where samples were cut, were chosen according to UT inspection as it was done for microscopy observation. Samples A, B and C were then scanned on computed tomography. Parameters of test: voltage: $40 \mathrm{kV}$, Current intensity: $230 \mu \mathrm{A}$, Resolution (voxel size): $13.15 \mu \mathrm{m}$, Focal point: $9.5 \mu \mathrm{m}$, Time exposure: $0.333 \mathrm{~s}$, Distance focal point - sample: $53.38 \mathrm{~mm}$, Distance focal point - detector: $811.52 \mathrm{~mm}$.

Before CT, samples A, B, and C were grinded and polished on one side to evaluate porosity from cross-section on microscope. After that, x-ray scan of each sample (with already grinded and polished one side) were done. According to sample scans, porosity was determined using software included in tomograph. Results compared with NDT are in Tab. 5. 
Tab. 5. Comparison of porosity measurements from CT and UT

\begin{tabular}{|c|c|c|c|c|c|c|c|c|}
\hline \multicolumn{2}{|c|}{ Sample A } & \multicolumn{3}{c|}{ Sample B } & \multicolumn{3}{c|}{ Sample C } \\
\hline & CT & UT & & CT & UT & & CT & UT \\
\hline Volume porosity & $1.52 \%$ & $2.2 \%$ & Volume porosity & $1.17 \%$ & $2.5 \%$ & Volume porosity & $1.63 \%$ & $1.2 \%$ \\
\hline
\end{tabular}

Samples A, B, C was prepared mention previously for microscopy observation from one side. This action allowed comparing 2D CT scans with microscopy results of the same plane on each sample (Fig. 9). Results are in Tab. 6.

Tab. 6. Comparison of porosity measurements from CT and MIC

\begin{tabular}{|c|c|c|c|c|c|c|c|c|}
\hline \multicolumn{3}{|c|}{ Sample A } & \multicolumn{3}{c|}{ Sample B } & \multicolumn{3}{c|}{ Sample C } \\
\hline & CT & MIC & & CT & MIC & & CT & MIC \\
\hline Cross-section & $0.59 \%$ & $1.152 \%$ & Cross-section & $0.47 \%$ & $0.885 \%$ & Cross-section & $0.65 \%$ & $0.832 \%$ \\
\hline
\end{tabular}
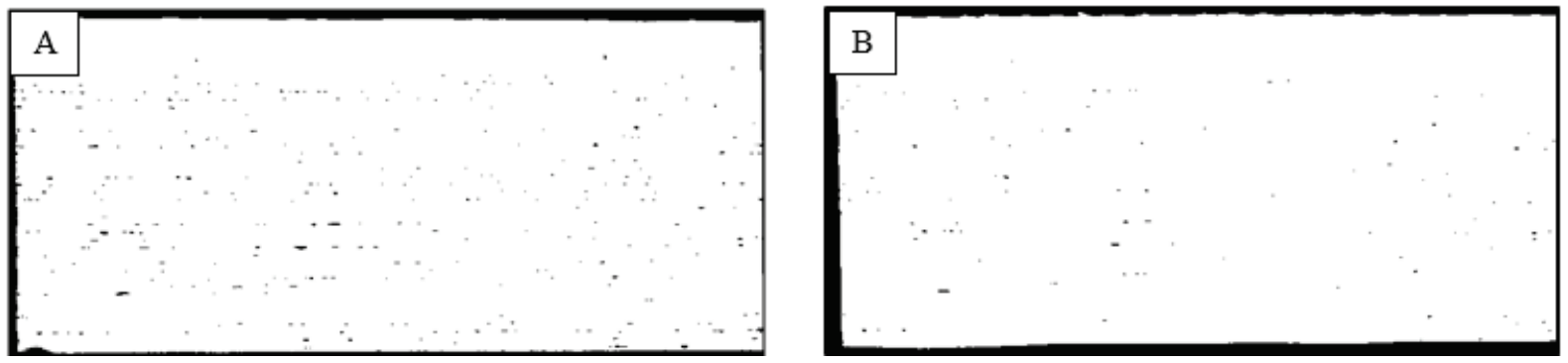

Fig. 9. Comparison of 2D cross-section images obtained from: A-microscope, B-computed tomography [A.J.2018]

According to UT prediction (Fig. 7), the lowest porosity should have sample C. A and B should have similar amount of porosity with a small predominance of sample B. CT scans shows different results. This could be another confirmation that during UT scans, final result contains real porosity and RRR (sample A, B).

Figure 9 shows the same cross-section area from sample B, seen on microscope and computed tomography. Picture from microscope has more visible porosity including much smaller voids. This explains the results from Tab. 6. Microscope on witch this results were obtained has bigger resolution in $2 \mathrm{D}$ measurement than tomograph.

\section{Fibber volume/void content}

Two composite material panels were tested. Samples were cut from different areas. Cutting main factor gives different expected porosity (shown in Fig. 7). Calculations of the test method were done using specials formulas (1-5). Results of test are presented in Tab. 7.

Tab. 7. Results of Fibber Volume tests

\begin{tabular}{|c|c|c|c|c|c|}
\hline $\begin{array}{c}\text { Sample } \\
\text { name }\end{array}$ & $\begin{array}{c}\text { Reinforcement } \\
\text { content }- \text { weight } \\
\text { percent, } W_{r}[\% \mathrm{wt}]\end{array}$ & $\begin{array}{c}\text { Reinforcement } \\
\text { content }- \text { volume } \\
\text { percent, } V_{r}[\%]\end{array}$ & $\begin{array}{c}\text { Matrix content } \\
- \text { weight percent, } \\
W_{m}[\% \mathrm{wt}]\end{array}$ & $\begin{array}{c}\text { Matrix Content } \\
- \text { volume percent, } \\
V_{m}[\%]\end{array}$ & $\begin{array}{c}\text { Void Volume, } \\
V_{v}[\%]\end{array}$ \\
\hline $05-1$ & 67.46 & 59.30 & 32.54 & 38.42 & 2.28 \\
\hline $05-2$ & 67.03 & 58.77 & 32.97 & 38.83 & 2.40 \\
\hline $05-3$ & 66.53 & 59.50 & 33.47 & 40.22 & 0.29 \\
\hline $05-4$ & 65.59 & 58.18 & 34.41 & 41.00 & 0.82 \\
\hline $05-5$ & 66.92 & 59.62 & 33.08 & 39.60 & 0.78 \\
\hline $05-6$ & 67.14 & 60.12 & 32.86 & 39.53 & 0.35 \\
\hline
\end{tabular}


Last of validation methods were Constituent Content, which is destructive test. Fibber volume test method was done with $150 \mathrm{ml}$ of sulfuric acid $\mathrm{H}_{2} \mathrm{SO}_{4} 96 \%$ on each sample. The temperature of heating was $280^{\circ} \mathrm{C}$. After the solution was dark, $270 \mathrm{ml}$ of hydrogen peroxide $\mathrm{H}_{2} \mathrm{O}_{2}, 30 \%$ were added to every nest beaker. When the resin was totally dissolved, vacuum filtration were done with distilled water.

As see on Tab. 7, range of results of the same composite material is considerable. The lowest score is $0.29 \%$ void volume, wherein 4 of tested samples had score above $2 \%$ void volume. Porosity, which became during on manufacturing process could be the cause of it. In reference to microscopy method (Tab. 2), constituent content test gave different results. Result differences between methods are shown in Fig. 10.

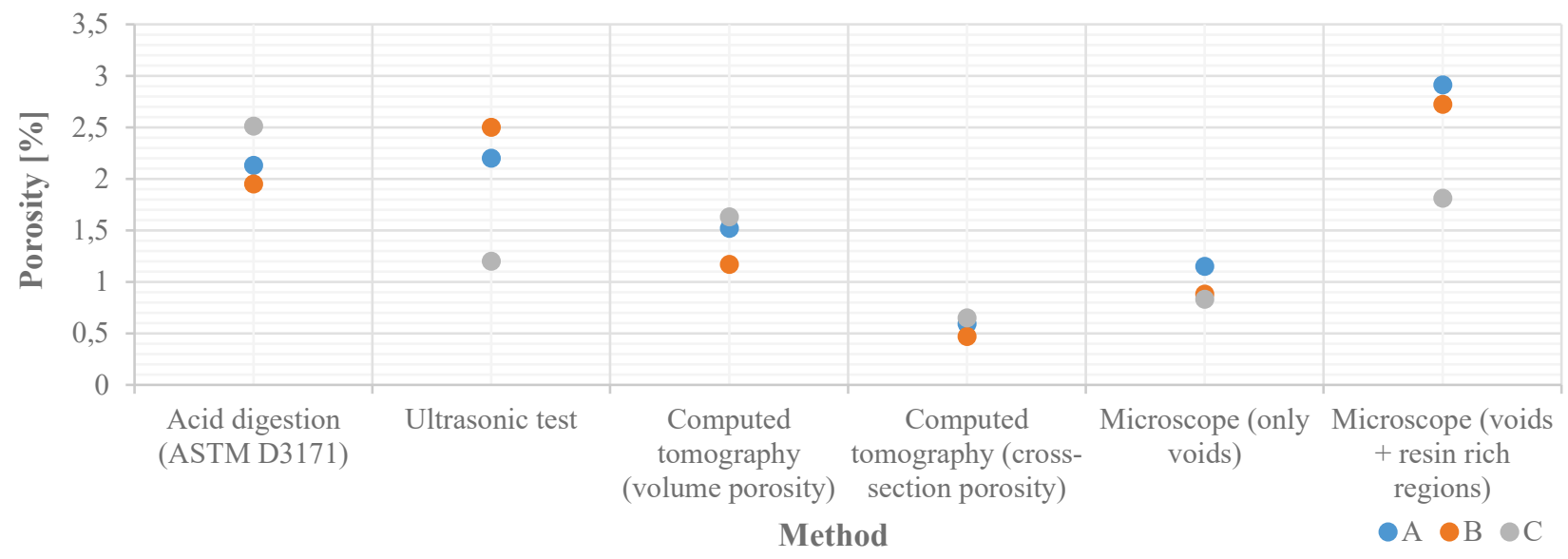

Fig. 10. Result differences between methods

\section{Conclusions}

Based on different (non-destructive and destructive) quality tools, conclusion about prediction and calculation of porosity inside CFRP composites were made:

1) Different testing methods give different results of porosity because of the mechanism of test.

2) Ultrasonic test in many cases is the first step to evaluate quality of the CFRP panel because of its easy assembly and good imaging of panel quality. Using UT, it is convenient to see regions of different quality of composite.

3) Biggest drawback of that method is difficulty to define kind of defects inside the composite.

4) Computed tomography seems to be the best method for quality inspection because of the mechanism of test (non-destructive, high resolution 3D images, x-ray source can "recognize" resin rich regions from voids) but it is expensive, time consuming and can be not enough inaccurate for small voids.

5) Chemical digestion of CFRP can give good results but it need to be done very precisely. Acid digestion, weighting, filtering and calculation all of that factors can affect the final result of porosity measurement. Additionally this method is destructive, dangerous and time consuming.

6) Microscopic observation gives very high quality $2 \mathrm{D}$ images and it is easy to recognize and count voids inside the sample. Based on grey scale, porosity cannot be count wrong which makes results very accurate. The main drawback of this method is that cross-section images represents only 2D picture of the structure. It is a result for only this exact area. It is hard to predict level of porosity, which is in deeper parts of the sample.

7) According to degree of porosity in CFRP, comparison of before mention methods is very difficult.

a) First thing is that all methods shows the same relationship which means, regions described as a low/high porosity degree in fact have it, 
b) Next is that, results from microscope are closer or even higher to this predicted from UT when resin rich regions are included into calculation (e.g. $2.2 \%$ from UT vs $1.152 \%$ (only voids) and $2.912 \%$ (voids + resin rich regions),

c) CT, UT and void content measured according to ASTM D3171 should give very similar results because all of this methods measure amount of porosity in whole sample volume. In fact they give similar but not exact results (e.g. UT: $2.2 \%$, CT: $1.52 \%$ and $2.13 \%$ for acid digestion),

d) Two dimensional porosity measurement results obtained from the same cross-sections, evaluated on CT and microscope looks similar (e.g. CT: 0.65\% vs MIC: $0.83 \%$ ). Higher results obtained from microscope was caused because higher images resolution,

e) 2D images from microscope can be comparable with other methods but to find a key or factor that will give similar results, need more tests.

\section{References}

[1] Zhang, A., Zhang, D., The Mechanical Property of CFRP Laminates with Voids, Advanced Materials Research, Vols. 652-654, pp. 25-28, 2013.

[2] Stamopoulos, A. G., Tserpes, K. I., Prucha, P., Vavrik, D., Evaluation of porosity effects on the mechanical properties of carbon fibre-reinforced plastic unidirectional laminates by $X$-ray computed tomography and mechanical testing, Journal of Composite Materials, $0(0)$, pp. 1-12, 2015.

[3] Grelsson, B., Correlations between porosity content, strength and ultrasonic attenuation in carbon fibre laminates, Materials \& Design, Vol. 13, No. 5, 1992.

[4] Bowkett, M., Thanapalan, K., Comparative analysis offailure detection methods of composites materials' systems, Systems Science \& Control Engineering: An Open Access Journal, Vol. 5, No. 1, pp. 168-177, 2017.

[5] ASTM D3171-15, Standard Test Method for Constituent Content of Composite Materials, American Society for Testing and Materials, 2015.

[6] ASTM D792-13, Standard Test Method for Density and Specific Gravity (Relative Density) of Plastics by Displacement, American Society for Testing and Materials, 2013.

[7] Cohen, D., Mantell, S. C, Zhao, L., The effect of fibre volume fraction on filament wound composite pressure vessel strength, Composite Part B: Engineering, Vol. 32, Iss. 5, pp. 413-429, Elsevier, 2001.

[8] Farhana, N. I. E, Abdul Majid, M. S., Paulraj, M. P., Ahmadhilmi, E., Fakhzan, M. N., Gibson, A.G., A novel vibration based non-destructive testing for predicting glass fibrel matrix volume fraction in composites using a neural network model, Composite Structures, Vol. 144, pp. 96-107, 2016.

[9] Sałacińska, A., Przeglad wymaganych badań fizyczno-chemicznych dla kwalifikacji materiałów kompozytowych, Prace Instytutu Lotnictwa, 2016.

[10] Stepniowska, A., Wplyw wybranych parametrów na poprawność przeprowadzania badań zawartości składników stałych w materiale kompozytowym, Prace Instytutu Lotnictwa, 2016.

[11] Reh, A., Visualization of Porosity in Carbon Fibber Reinforced Polymers, PhD thesis, Vienna University of Technology, 2015.

[12] Madra, A., El Hajj, N., Benzeggagh, M., X-ray microtomography applications for quantitative and qualitative analysis of porosity in woven glass fibre reinforced thermoplastic, Composites Science and Technology, No. 95, pp. 50-58, 2014.

[13] Garcea, S. C., Wang, Y., Whiters, P. J., X-ray computed tomography of polymer composites, Composites Science and Technology, No. 156, pp. 305-319, 2018.

[14] Lin, L., Luo, M., Tian, H. T., Li, X. M., Guo, G. P., Experimental investigation on porosity of carbon fibre-reinforced composite using ultrasonic attenuation coefficient, $17^{\text {th }}$ World Conference on Nondestructive Testing, Shanghai, China, 25-28 October 2008.

Manuscript received 09 September 2019; approved for printing 19 December 2019 